\title{
Effects of Sub-Lethal Atrazine Concentrations on Embryogenesis, Larval Survival and Growth of African Catfish, Clarias gariepinus (Burchell, 1822)
}

\author{
Prosper Ashibudike Opute ${ }^{1,2, *}$ (D) , ljeoma Patience Oboh ${ }^{1}$
}

\begin{abstract}
${ }^{1}$ University of Benin, Faculty of Life Sciences, Department of Animal and Environmental Biology, Benin City, Nigeria. ${ }^{2}$ North-West University, Faculty of Natural and Agricultural Sciences, Department of Zoology, Unit for Environmental Sciences and Management, Potchefstroom, South Africa.
\end{abstract}

\section{Article History}

Received 06 May 2020

Accepted 20 October 2020

First Online 20 October 2020

\section{Corresponding Author}

Tel.: +2348033644134

E-mail: ashibudike.opute@uniben.edu

\section{Keywords \\ Toxicity \\ Fertilized eggs \\ Cleavage \\ Morphometry \\ Deformities}

\begin{abstract}
The toxicity of environmentally relevant concentrations of atrazine on exposed fertilized eggs of Clarias gariepinus was evaluated in a 96hour static non-renewal bioassay. After exposure to atrazine concentrations of 0 (control), 4, 8, 12, and $16 \mu \mathrm{gL}$ 1 in water, first mitotic cleavage in the control occurred at 40 minutes after fertilization. The first cleavage did not occur in the $8 \mathrm{\mu gL}^{-1}$ treatment group until 60 minutes after fertilization. Similar dose depended delayed cleavage was observed across atrazine exposed eggs. The first larvae emerged 22 hours from the time of fertilization at $27.0^{\circ} \mathrm{C}$ in both control and atrazine treatment groups. However, hatching rates significantly differed between the control and atrazine exposed eggs $(P<0.05)$ with $73.3 \%$ hatching rate in the control and $3.3 \%$ among the exposed eggs treated with $16 \mu \mathrm{LL}^{-1}$ of atrazine. Among the morphological deformities observed in the larvae of atrazine exposed eggs, kyphosis occurred more frequently with $60 \%$ of emerged larvae in the $16 \mu \mathrm{gL}^{-1}$ atrazine treated group exhibiting the deformity. Morphometry showed significantly reduced head length, body length, body weight, and yolk diameter in $16 \mu \mathrm{gL}-1$ atrazine exposed eggs compared to the control. These results indicate that atrazine disrupted embryonic process and delayed hatching with severe larvae deformities.
\end{abstract}

\section{Introduction}

The quest for food security has raised many questions about how to feed the world's increasing population. The need to produce a greater quantity and quality of food to adequately feed the teeming population has left governments and farmers with no choice but to encourage intensified farming beyond the scale subsistence. However, agricultural mechanization cannot be separated from the use of pesticides and other agricultural chemicals to promote and improve the quantity and quality of farm produce. This has rendered pesticides an indispensable resource for largescale agricultural production Atrazine, a class III herbicide of the triazine family is the most common pesticides used by farmers in most developing countries including Nigeria (Uddin et al., 2015). For example, eighty per cent of Nigeria's farmland is managed by smallholders who work up to 10 hectares (Mgbenka et al., 2015). Despite this degree of utility, data paucity exists on the fate and effects of these chemicals after initial spreading to crop fields in those regions where farmers misunderstand safe practices and associated health risks. Therefore, understanding the magnitude of possible adverse reproductive and developmental outcomes in C. gariepinus, a Pan-African and popular food fish in most African countries like Nigeria correlated with exposure to a widely used pesticide such as atrazine, will be an invaluable tool in evaluating ecological risk and controlling pesticides for the ecosystem.

C. gariepinus (Burchell, 1822) is one of the freshwater fishes most common in Africa (Nguyen and Janssen, 2002). It inhabits tropical swamps, lakes and 
rivers (De Graaf \& Janssen, 1996). In the last decade, $C$. gariepinus was introduced for agricultural purposes in Europe, Asia and Latin America (Gomaah and Naggar, 2004, Gavriloaie, and Chişamera, 2005). Female African catfish have fully developed ovaries that contain ripe eggs throughout the year if kept at water temperatures above $22^{\circ} \mathrm{C}$ in ponds. The African catfish fry and fingerlings are hard to obtain in natural water. Alternatively, induction of spawning by hormone injection (Huisman and Richter, 1987) using carp pituitary suspension (Hogendoorn and Vismans, 1980), human chorionic gonadotropin (Eding et al., 1982), 17hydroxy progesterone (Richter et al., 1985) or synthetic luteinizing hormone-releasing hormone analogues (Huisman and Richter, 1987) can be obtained artificially. Carp-pituitary powder is most commonly used in artificial spawning in catfish culture in Asian and African countries. Improved methods for artificial reproduction have recently been developed for the African catfish. According to Kucharczyk et al. (2019), splitting the semen used for insemination into smaller aliquots and applying it to the eggs within 90 seconds has increased the percentage of larvae hatching after adding water for egg activation. Similarly, Müller et al. (2020) evaluated the time-dependent fertilization capacity of sperm introduced into the ovary. They concluded that the improved approach could combine the simplicity of induced spawning with less time-dependent sperm delivery compared to traditional in vitro fertilization. Due to its extensive use in aquaculture, the economic importance of this species has enormously increased in recent years (Ponzoni and Nguyen, 2008, De Graaf and Janssen, 1996). In addition to this, natural population of C. gariepinus forms a staple diet for a large number of subsistence farmers across Africa. Despite its great economic importance in aquaculture, short developmental time, ease of cultivation and year-round reproduction, its fertilization, embryonic and ontogenetic development lack information about the effects of herbicide toxicity.

Besides being an excellent aquaculture candidate because of its short culture time, high fecundity, rapid egg and larvae development and high meat quality, $C$. gariepinus has also been used in basic research and ecotoxicological work (Nguyen et al., 1999; Nguyen and Janssen, 2002; Olaifa et al., 2003). However, the use of only one developmental stage in toxicity testing is not adequate for the risk assessment of chemicals; thus, the use of different developmental stages of organisms in ecotoxicology research could be more informative (Honkanen, 2004). Although atrazine has been documented to affect embryos of some fish models such as Danio rerio and Pimephales promelas embryos, its effects on embryos of $C$. gariepinus are not very well reported. The present toxicological study, therefore, focuses on the effects of atrazine toxicity in various developmental stages of $C$. gariepinus from fertilization to the end of the endogenous feeding period, with a focus on the seven broad stages of embryogenesis: zygote, cleavage, morulation, blastulation, gastrulation, segmentation and hatching, as well as growth and survival.

\section{Materials and Methods}

\section{Test Chemical}

The test chemical was atrazine (CAS number 191224-9) manufactured by the Zhejiang Zhongshan chemical industry group, China, with a brand name, AltraForce. AtraForce ${ }^{\circledR} 50$ per cent (\%) SC was obtained in a one-litre container at a concentration of $39.685 \mathrm{gL}^{-1}$. A stock solution was prepared from the $39.685 \mathrm{gL}^{-1}$ by adding $1 \mathrm{ml}$ of the herbicide to $999 \mathrm{ml}$ of water (Reish and Oshida, 1987). The stock solution was then used by diluting estimated amounts of the toxicant with dechlorinated tap water to prepare different nominal concentrations of the toxicant. The control solutions had no toxicant but dechlorinated tap water.

\section{Experimental Design and Treatment}

C. gariepinus male and female broodstock were artificially spawned at a rate of $0.5 \mathrm{ml} / \mathrm{kg}$ of body weight by intramuscular injection of Ovaprim manufactured by Syndel Canada. For ease of injection and stripping of eggs, the broodstock was anaesthetized with five drops of quinaldine (added into 3 liters of water in plastic bowls). A single dose of ovaprim was injected intramuscularly $(2-3 \mathrm{~cm})$ in the direction of the tail at an angle of $30-45^{\circ}$ of the dorsal fin. Injected fish were kept in separate tanks and allowed a latency time of 11 hours. After 11 hours (latency period) the injected female broodstock was removed from its tank, weighed and then stripped by gently pressing the abdomen from the pectoral fin to the genital papilla into well labelled dry bowls with the thumb. After dissecting it, male broodstock milt was extracted, and the sperm collected by testis laceration with a clean razor blade into $25 \mathrm{ml}$ of normal saline $(0.9 \% \mathrm{NaCl}$ in water) in a tub. The male's sperm was mixed with the female's eggs and spread over a plastic netting substrate mounted in a $50 \mathrm{~L}$ bowl that held about $20 \mathrm{~L}$ of water. The water temperature used was $27^{\circ} \mathrm{C}$, and the $\mathrm{pH}$ was 6.6 (controlled using soda ash and measured using a portable $\mathrm{pH}$-meter). Thirty (30) eggs were counted and removed from the original mixture and spread in smaller bowls containing $2 \mathrm{~L}$ of water to be used for embryo-toxicity on a netting substrate. That was achieved for each of the four (4) concentrations of atrazine egg-sperm mixtures. The small and large bowls were all correctly labelled with the $A T_{1}, A T_{2}, A T_{3}, A T_{4}$ and $C$ codes representing atrazine concentrations of $4 \mu \mathrm{gL}^{-1}, 8 \mu \mathrm{gL}^{-1}, 12 \mu \mathrm{gL}^{-1}, 16 \mathrm{\mu gL}^{-1}$ and control, respectively. These concentrations represent environmentally relevant concentrations $\left(1 \mu \mathrm{gL}^{-1}\right)$ and naturally occurring concentrations $\left(20 \mathrm{gL}^{-1}\right)$ of atrazine (Scahill, 2008). The embryo-toxicity test was conducted by the exposure to atrazine of freshly fertilized eggs 
(before the beginning of cleavage i.e 40minutes postfertilization). Microscopic examination of embryonic development began immediately after fertilization (first 3 hours at 5 minutes intervals, then at hourly and twohourly intervals until the post-hatching stage was 72hours.

\section{Observation of Embryonic Development}

In 5 batches of 10 eggs per batch, fertilized eggs were collected at random from incubating tanks into a petri dish. Embryonic development was observed, monitored and documented live, using a light microscope (Unico Binocular Microscope G380) connected to a computer with its digital camera. Immediately after fertilization, selected eggs were viewed under the microscope for the first 3 hours at 5 minutes intervals, then at hourly and two-hourly intervals before hatching. At a magnification of x1000 for 22 hours, the developmental stages of eggs beginning from the first cleavage to hatching were studied microscopically. Embryos were then placed back into their containers after observation. Bending embryos within the eggs were removed as development began because they could not be measured repeatedly. The precise timing and detailed description of each stage were recorded.

\section{Morphological Observations in Post-Hatching Stages}

A light microscope with a digital camera connected to a laptop was used to record gross malformations. The observed parameters include yolk sac, body curvature, the formation of somites, formation of germ rings and invagination of the embryos. Using Carl Zeiss 1016-758 Axioskop 2 plus and Carl Zeiss 1016-758 Axioskop 2 plus imaging software and Fiji image analysis software, morphometric assessment of hatched larvae was performed.

\section{Growth}

Measurements were taken for each larva. Using Carl Zeiss 1016-758 Axioskop 2 plus and Carl Zeiss 1016758 Axioskop 2 plus imaging software and Fiji image analysis software, the total body length $(\mathrm{mm})$, head length $(\mathrm{mm})$, body width $(\mathrm{mm})$ and yolk diameter $(\mathrm{mm})$ were measured and reported on a data collection sheet.

\section{Data Analysis}

Data across exposure concentrations were analyzed using Statistical Package for Social Sciences (SPSS version 21) for growth measurements. Data were expressed as mean \pm standard error of the mean (SEM). One-way analysis of variance (ANOVA) was used to test for significance followed by a posthoc Tukey's multiple tests, for statistical comparisons among the groups. Differences between means were considered significant at $\mathrm{P}<0.05$.

\section{Results and Discussion}

\section{Physico-Chemical Properties of the Test Media}

The results of the physicochemical parameters were almost the same across treatment groups (Table 1) and were within the desirable range for fish culture throughout the duration of the experiment. The parameters showed no significant differences $(P>0.05)$ from the control. The observed stability of the water quality characteristics showed that atrazine did not adversely reduce the water quality in the treatment tanks. Our findings are consistent with the report of Papoulias et al. 2014 on atrazine. They reported that atrazine exposure to Japanese medaka (Oryzias latipes) measured with ELISA remained fairly constant and near nominal concentrations for the entire duration of the experiment.

\section{Morphological Events During Embryonic Development}

\section{Fertilization to Hatching}

At $27^{\circ} \mathrm{C}$ it was observed that fertilized eggs were sticky, transparent and spherical with a mean diameter of $1.10 \pm 0.21 \mathrm{~mm}$. The timing of cleavage, morula, blastula and gastrula in the $27^{\circ} \mathrm{C}$ control tanks differed slightly from those reported earlier by Sule and Adikwu, (2004) at $25^{\circ} \mathrm{C}$. The minor variation in the timing of developmental events could be due to temperature differences. The summary of the various stages and timing of $C$. gariepinus exposure to different concentrations of atrazine during embryonic development at $27^{\circ} \mathrm{C}$ is presented in table 2 . The first cleavage in the control group occurred at about 40 minutes, and at 80 minutes post-fertilization, the $16-32$

Table 1. Concentrations of the physico-chemical parameters of the test media of $C$. gariepinus during embryonic development

\begin{tabular}{|c|c|c|c|c|c|c|c|}
\hline Concentration & $0.00 \mu \mathrm{gL}-1$ & $4.00 \mu \mathrm{gL}-1$ & $8.00 \mu \mathrm{gL}-1$ & $12.00 \mu \mathrm{gL}-1$ & $16.00 \mu \mathrm{gL}-1$ & $P$-Value & Significance \\
\hline Parameter & Mean \pm SD & Mean \pm SD & Mean \pm SD & Mean \pm SD & Mean \pm SD & & \\
\hline Temperature (OC) & $27.37 \pm 0.39 a$ & $27.39 \pm 0.39 a$ & $27.41 \pm 0.37 a$ & $27.38 \pm 0.35 a$ & $27.46 \pm 0.35 a$ & 0.984 & $P>0.05$ \\
\hline $\mathrm{pH}$ & $7.02 \pm 0.09 a$ & $7.00 \pm 0.08 a$ & $7.00 \pm 0.11 \mathrm{a}$ & $7.03 \pm 0.12 a$ & $7.04 \pm 0.13 a$ & 0.949 & $P>0.05$ \\
\hline Conductivity $(\mu \mathrm{S} / \mathrm{cm})$ & $102.20 \pm 0.92 a$ & $102.30 \pm 0.95 a$ & $102.00 \pm 0.95 a$ & $102.20 \pm 0.92 a$ & $101.10 \pm 0.88 a$ & 0.978 & $P>0.05$ \\
\hline Turbidity (mg/l) & $0.23 \pm 0.02 a$ & $0.24 \pm 0.03 a$ & $0.24 \pm 0.03 a$ & $0.24 \pm 0.02 a$ & $0.23 \pm 0.02 a$ & 0.421 & $P>0.05$ \\
\hline Alkalinity (mg/l) & $17.43 \pm 0.43 a$ & $17.55 \pm 0.36 a$ & $17.53 \pm 0.43 a$ & $17.46 \pm 0.49 a$ & $17.50 \pm 0.44 a$ & 0.970 & $P>0.05$ \\
\hline Hardness(mg/l) & $32.52 \pm 0.37 a$ & $32.57 \pm 0.40 a$ & $32.48 \pm 0.33 a$ & $32.46 \pm 0.33 a$ & $32.50 \pm 0.34 a$ & 0.974 & $P>0.05$ \\
\hline $\mathrm{DO}(\mathrm{mg} / \mathrm{l})$ & $8.11 \pm 0.12 a$ & $8.13 \pm 0.13 a$ & $8.12 \pm 0.13 a$ & $8.14 \pm 0.10 a$ & $8.12 \pm 0.14 a$ & 0.987 & $P>0.05$ \\
\hline
\end{tabular}


Table 2. Time and percentage (\%) occurrence of morphological events during embryonic periods across control and treatment groups of Clarias gariepinus exposed to atrazine immediately after fertilization

\begin{tabular}{lcccccc}
\hline $\mathrm{S} / \mathrm{N}$ & Developmental stages & $0 \mu \mathrm{gL}^{-1}$ Minutes $(\%)$ & $4 \mu \mathrm{gL}^{-1}$ Minutes $(\%)$ & $8 \mu \mathrm{gL}^{-1}$ Minutes $(\%)$ & $12 \mu \mathrm{gL}^{-1} \mathrm{Minutes}_{(\%)}$ & $16 \mu \mathrm{gL}^{-1} \mathrm{Minutes}^{(\%)}$ \\
\hline 1. & Fertilized egg & $0(100.0)$ & $0(100.0)$ & $0(100.0)$ & $0(100.0)$ & $0(100.0)$ \\
2. & Blastodisc & $30(76.7)^{\mathrm{a}}$ & $30(60.0)^{\mathrm{b}}$ & $30(46.6)^{\mathrm{c}}$ & $30(36.7)^{\mathrm{c}}$ & $30(13.3)^{\mathrm{d}}$ \\
3. & 2-Cell stage & $40(80.0)^{\mathrm{a}}$ & $60(46.7)^{\mathrm{bc}}$ & $60(36.7)^{\mathrm{c}}$ & $70(30.0)^{\mathrm{c}}$ & $70(3.3)^{\mathrm{d}}$ \\
4. & 4-Cell stage & $60(73.3)^{\mathrm{a}}$ & $70(40.0)^{\mathrm{b}}$ & $70(26.7)^{\mathrm{c}}$ & $80(6.6)^{\mathrm{d}}$ & $85(6.6)^{\mathrm{d}}$ \\
5. & 8-Cell stage & $70(70.0)^{\mathrm{a}}$ & $80(30.0)^{\mathrm{bc}}$ & $80(20.0)^{\mathrm{c}}$ & $90(6.6)^{\mathrm{d}}$ & $95(3.3)^{\mathrm{d}}$ \\
6. & $16-32-C e l l$ stage & $80(60.0)^{\mathrm{a}}$ & $90(23.3)^{\mathrm{b}}$ & $105(13.3)^{\mathrm{c}}$ & $110(10.0)^{\mathrm{c}}$ & $115(3.3)^{\mathrm{d}}$ \\
\hline
\end{tabular}

*Time (minutes) of occurrence of morphological events during embryonic periods is indicted under each treatment concentrations while the percentage (\%) of occurrence appeared in parenthesis.

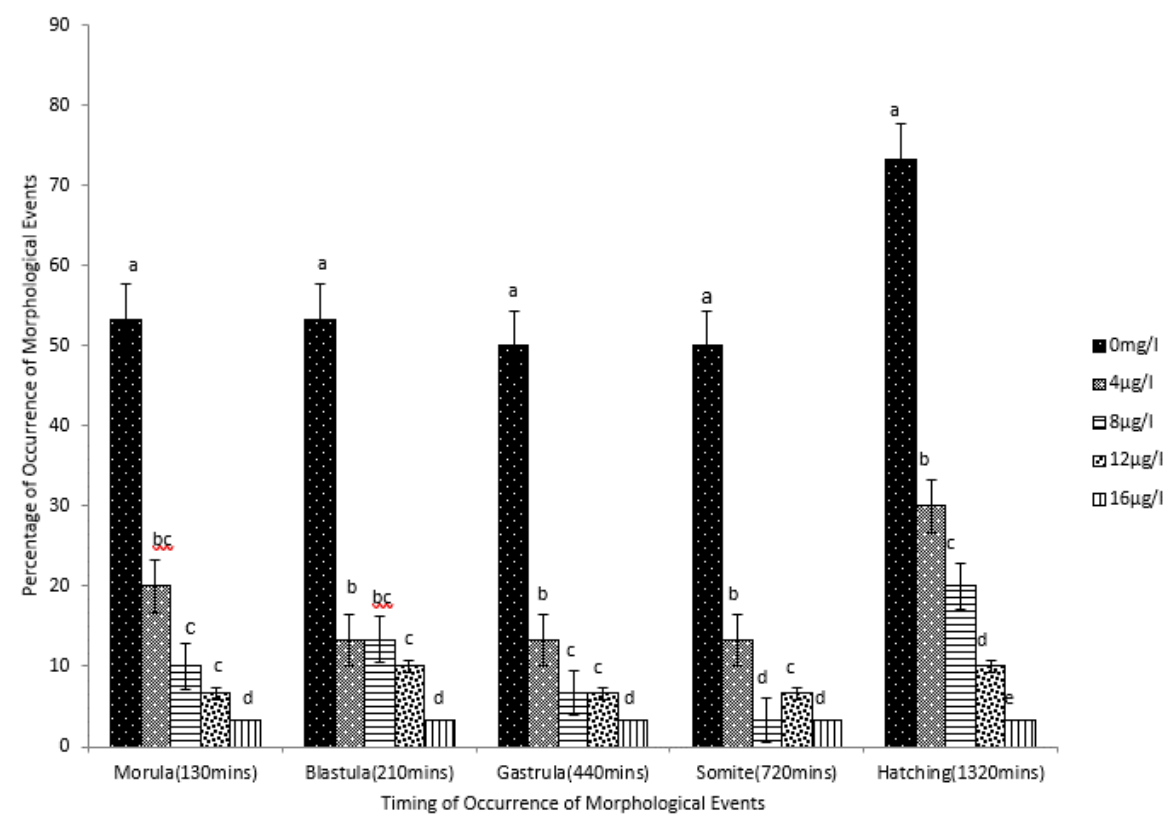

Figure 1. Time and percentage (\%) occurrence of morphological events from morula stage to hatching across control and treatment groups of Clarias gariepinus exposed to atrazine immediately after fertilization.

cell stage was reached. In the treatment group exposed to $4 \mathrm{\mu gL}^{-1}$ of atrazine, cleavage did not begin until 60 minutes after fertilization. At 60minute, however, cleavage had yet to continue at higher concentrations of atrazine $\left(12 \mu \mathrm{gL}^{-1}\right.$ and $\left.16 \mathrm{\mu gL}^{-1}\right)$. Before the beginning of cleavage, calcium waves are initiated at fertilization to stimulate the contraction of the actin cytoskeleton which will squeeze the non-yolky cytoplasm into the animal pole of the egg. This converts the spherical egg into a more pear-shaped structure, with an apical blastodisc (Leung et al., 1998). The delay in the initiation of cleavage in the higher atrazine concentrations could have resulted from the interference of the process of stimulation of the actin cytoskeleton by atrazine. At 90 minutes post fertilization, $23.3 \%$ of embryos in the treatment group exposed to $4 \mathrm{\mu gL}^{-1}$ of atrazine reached $16-32$ cell stage. Only $13.3 \%$ and $10.0 \%$ of embryos reached the 32-cell stage division in the treatment groups, $8 \mu \mathrm{gL}^{-1}$ and $12 \mathrm{\mu gL}^{-1}$ respectively, at 105 minutes. Just $3.3 \%$ of the embryos in the treatment group (16 $\mu \mathrm{gL}^{-1}$ ) reached the $16-32$ cell stage at 115 minutes. The delay in embryonic development found throughout the treatment groups from blastulation to hatching was dose-dependent and can be related to both oxidative- induced stress and mitotic alteration caused by atrazine exposure. Lugowska and Witeska (2008) reported that, during cleavage, Cyprinus carpio eggs exposed to lead $(\mathrm{Pb})$, copper $(\mathrm{Cu})$ and cadmium ( $\mathrm{Cd}$ ) showed distinct abnormalities with unequal and irregularly distributed blastomeres and deformed the entire blastula. Findings from this study revealed that atrazine during the embryogenesis of $C$. gariepinus may have inhibiting effects on mitotic division resulting in altered embryonic development, general delay in embryonic development and unfinished epiboly leading to retardation in organogenesis.

Treatment concentrations exposed to atrazine 8 $\mu \mathrm{g} / \mathrm{l}, 12 \mu \mathrm{g} / \mathrm{l}$ and $16 \mu \mathrm{g} / \mathrm{l}$ at seven hours Post-fertilization demonstrated irregular development of germ ring during gastrulation. This observation is similar to the findings of Anguiano et al. (2001), which reported decreased gastrula formation, gastrula arrest and abnormal furrow segmentation along with irregular blastomeres in Lindane-exposed Bufo arenarum embryos, an organochlorine chemical variant of hexachlorocyclohexane used both as an agricultural insecticide and as a pharmaceutical treatment for lice and scabies. Green et al. (1997) also documented 
gastrulation disturbance, irregular cleavage, and gut development in the violet sea urchin, Strongylocentrotus purpuratus exposed to methoxychlor, a synthetic organochlorine used as an insecticide.

In the control tank, hatching started 22 hours after fertilization, with an embryo hatching of $73.3 \%$ (Figure 1). The aggressive motion of the tail to either side was observed against the chorion wall, accompanied by contraction. As a result, the chorion wall breaks and hatching occurred. In the cephalic region, primary organ development was clearly identified (Figures 2A and 2B). While hatching occurred in other treatment groups, cephalic organs had yet to form (Figures 2C, 2D, and 2E). In treatment groups, 30\%, 20\%, 10\% and 3.3\% of embryos hatched respectively in treatment concentrations of $4 \mu \mathrm{gL}^{-1}, 8 \mu \mathrm{gL}^{-1}, 12 \mu \mathrm{gL}^{-1}$ and $16 \mathrm{\mu gL}^{-1}$, a clear indication of a dose-dependent delayed hatching. At 48 hours post-fertilization stage in the control tank, the total percentage of hatched embryos was $90 \%$. However, at 48 hours post-fertilization, the percentage of embryos hatched in $4 \mathrm{\mu gL}^{-1}$ and $8 \mathrm{\mu gL}^{-1}$ treatment concentrations was $30 \%$ and $10 \%$ respectively, while there was no surviving hatchling at the $16 \mu^{-1}$ treatment concentration. Jezierska et al., (2009) attributed structural and functional disruptions as responsible for the reduced number of hatched larvae during embryonic development. According to their results, the common carp's hatching performance (hatchability) was above $70 \%$ under optimal conditions, while that of metal-exposed embryos was much lower (34\%). Results in this study showed that the control group had $86.7 \%$ hatching success at $27^{\circ} \mathrm{C}$, while the lowest hatchability (16.7\%) of the atrazine-exposed embryo occurred at the highest concentration $\left(16 \mu \mathrm{gL}^{-1}\right)$ of the procedure. Therefore, it can be inferred that structural and functional changes caused by exposure to atrazine may be responsible for the decreased hatchability found across treatment groups.

\section{Morphological Aberrations During Embryonic and Post-Hatching Stages}

Different forms of spinal cord (notochordal) curvature has been reported in all four treatment groups: No notochordal abnormality was identified in the control group at $48 \mathrm{~h}$ post-fertilization. Nevertheless, in the $4 \mu \mathrm{gL}-1$ treatment group, $13.3 \%, 26.6 \%$ and $13.3 \%$ frequency of abnormalities were recorded for C-shaped body curvature, kyphosis, and lordosis respectively (Figure 3). Kyphosis was observed to occur more often in all treatment groups. The curvature of the spinal cord was less frequently observed in the $96 \mathrm{~h}$ postfertilization since the majority of this malformation was lethal. Linda et al. (1992) identified scoliosis to be associated with a variety of congenital anomalies, including neural tube deficiencies, caudal regression syndrome, and vertebrate fetal skeletal dysplasia. According to Mochida et al. (2009), the inhibition of acetylcholinesterase activity resulted in vertebral deformities in Fundulus heteroclitus larvae exposed to copper pyrithione. Developmental defects may also result from chemical genotoxic activity as reported by different authors (Cavas et al. 2005; Rocha et al. 2010; Ozkan et al. 2011). Exposure to toxic substances (Jezierska et al. 2000) and petroleum derivatives (Sisman et al. 2016) have been reported to be the major cause of deformation in fish larvae. However, biotic factors can also affect the quality of gametes, embryos, and larvae, in addition to abiotic factors. These biotic factors include egg over maturing (often referred to in the literature as 'egg-ageing'), e.g. asynchronous ovulation (Samarin et al. 2015). These studies show that the fertilization of overmature eggs not only causes deformation in offspring but also changes in the level of ploidy (Samarin et al. 2017). Nowosad et al. (2018) also reported that the delayed fertilization of post-ovulatory aged (over-mature) oocytes in the ovary negatively affected the quality of offspring, which resulted in decreased survival 3 days after fertilization and hatching, as well as increased incidence of different developmental defects. However, the notochordal defects found in this study may have been the result of the gastrula deformities observed during embryogenesis that may have been caused by atrazine toxicity, inhibition of acetylcholinesterase activity, and atrazine genotoxic action since all the eggs were harvested from the same broodstock at the same time.

\section{Embryo Survival}

Atrazine exposure during the embryonic development was observed to significantly decrease embryo survival and thus their hatching success. Development did not progress in most deformed embryos, and a few normally developed embryos in the control group. Highest embryo mortality occurred within the first 48 hours of the post-hatching stage with about $10 \%$ mortalities occurring under control conditions in the 24 post-hatching stage (Figure 4). Nevertheless, maximum embryo mortality before hatching occurred at the blastula stage of development across atrazine treatment groups. At this point, mortality could be attributed to the embryo's inability to continue the process of development. Ługowska (2005), reported the highest mortality rates at the blastula stage of common carp (C. carpio) embryonic development exposed to roundup, a glyphosate pesticide. Mortality from gastrulation to body segmentation (somite stage) was much lower before hatching between control and treatment groups. This report is similar to the results obtained by Słomin'ska (1998) who reported very low mortality during organogenesis between the body segmentation and eye pigmentation stage in lead and copper exposed common carp (C. carpio). The survival of the exposed embryos was dose-dependent across treatment groups with increasing mortalities up till 96 post-hatching stage suggesting that atrazine may have 

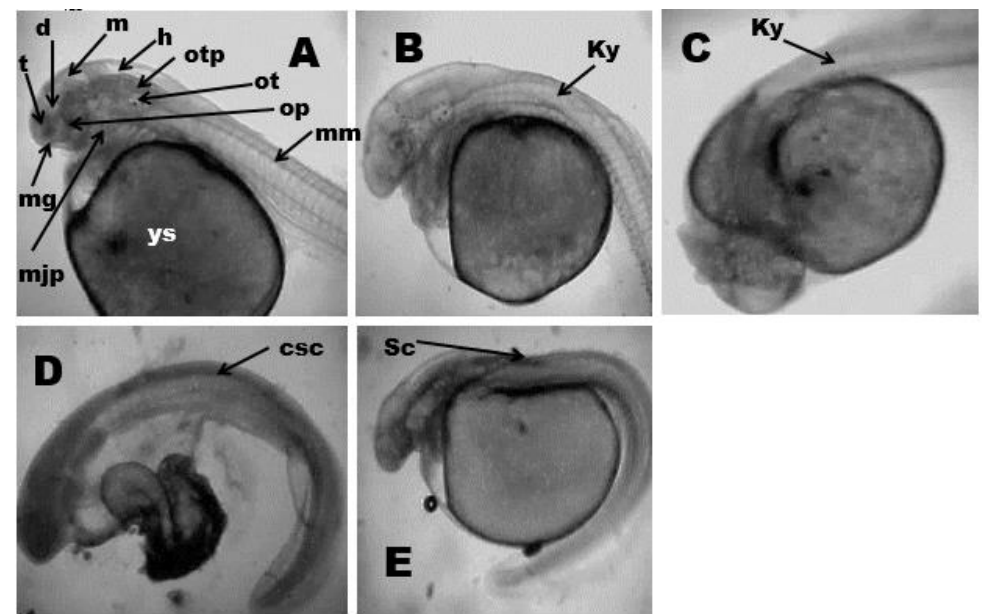

Figure 2. Embryonic developmental stages in Clarias gariepinus 22h-Post-Fertilization. A - control, B- $\mathrm{AT}_{1} ; \mathbf{C}-\mathrm{AT}_{2} ; \mathrm{D}-\mathrm{AT}_{3} ; \mathrm{E}-\mathrm{AT}_{4}$, $(\times 40) . \mathrm{t}-$ telencephalon; d-diencephalon; op-optic primordium; mm-myotomal muscle; m-mid-brain; h-hind-brain; ot-otoliths; otp-oticplacode; mg-mouth gape; mjp-mouth and jaw primordia; ys-yolk sac; ky-kyphosis; ky-kyphosis; dy- detached yolk; csc- c-shaped body curvature; sc-scoliosis.

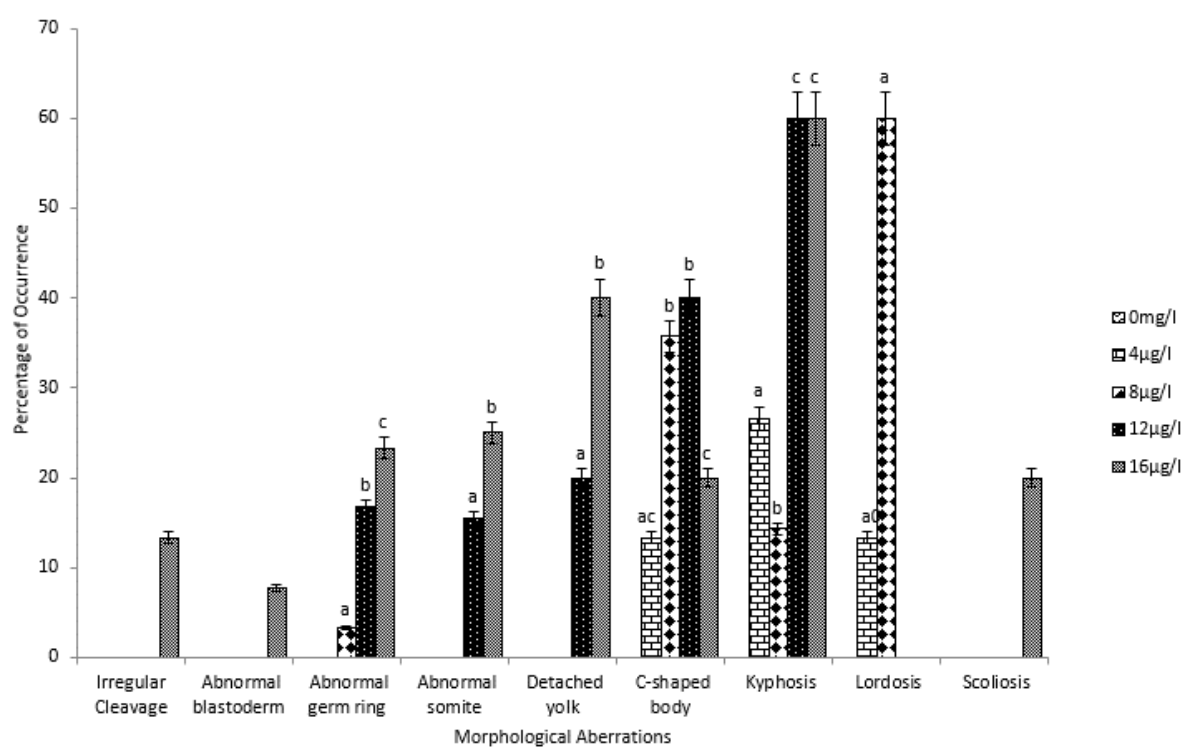

Figure 3. Percentage (\%) cumulative deformities during embryonic and post-embryonic periods across control and treatment groups of Clarias gariepinus exposed to atrazine immediately after fertilization.

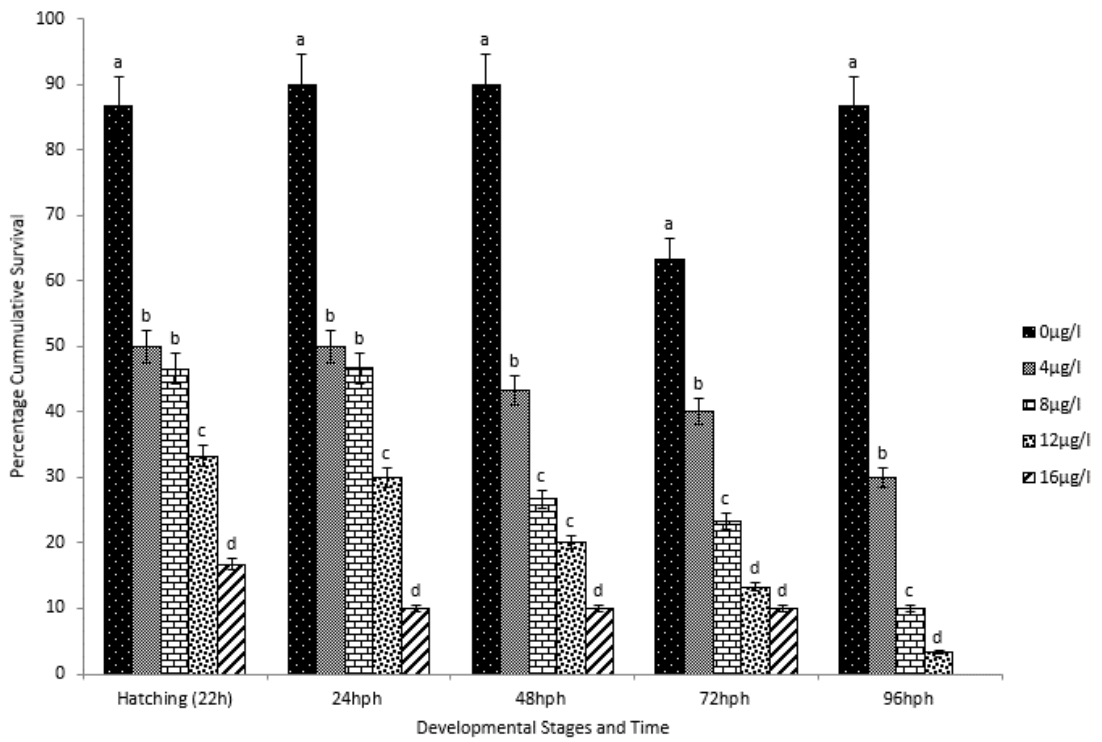

Figure 4. Percentage (\%) cumulative survival during embryonic and post-embryonic periods across control and treatment groups of Clarias gariepinus exposed to atrazine immediately after fertilization. 
congenital physiological effects that inhibited their survival.

\section{Embryo Morphometric Assessment}

Results from morphometric analysis of embryonic exposure of $C$. gariepinus to atrazine showed significant $(P<0.05)$ and dose-dependent reduction in the total length and head length across treatment concentrations compared to the control (Figure 5 and 6). Body width and yolk diameter across treatment concentrations were significantly $(P<0.05)$ different from the control (Figure 7 and 8). Larvae characteristics showed the same trend between 24-hour post-hatching and 72-hour posthatching. The total length of $C$. gariepinus larvae in the control group at 24-hour post-hatching was $4.13 \pm 0.06 \mathrm{~mm}$ while there was a significant reduction to
$3.66 \pm 0.42$ in the treatment group exposed to $16 \mu \mathrm{gL}-1$ of atrazine (Figure 5). Head length of the control group at 24 -hour post-hatching was $1.06 \pm 0.11 \mathrm{~mm}$, with $0.90 \pm 0.06 \mathrm{~mm}$ recorded for $16 \mu \mathrm{gL}-1$ treatment concentration (Figure 6). The reduction in head length observed may have serious developmental implication leading to microcephaly, a condition where the head is smaller than normal because the brain has not developed properly or has stopped growing. Medically, microcephaly may be caused by genetic abnormalities or by drugs, alcohol, certain viruses, and toxins that are exposed to developing embryo and damage the developing brain tissue. The reduced total length of embryo observed among atrazine treated groups, can be attributed to oxidative stress resulting from the presence of atrazine in the embryo. Dennery et al. (2007) reported that the embryo is more or less prone

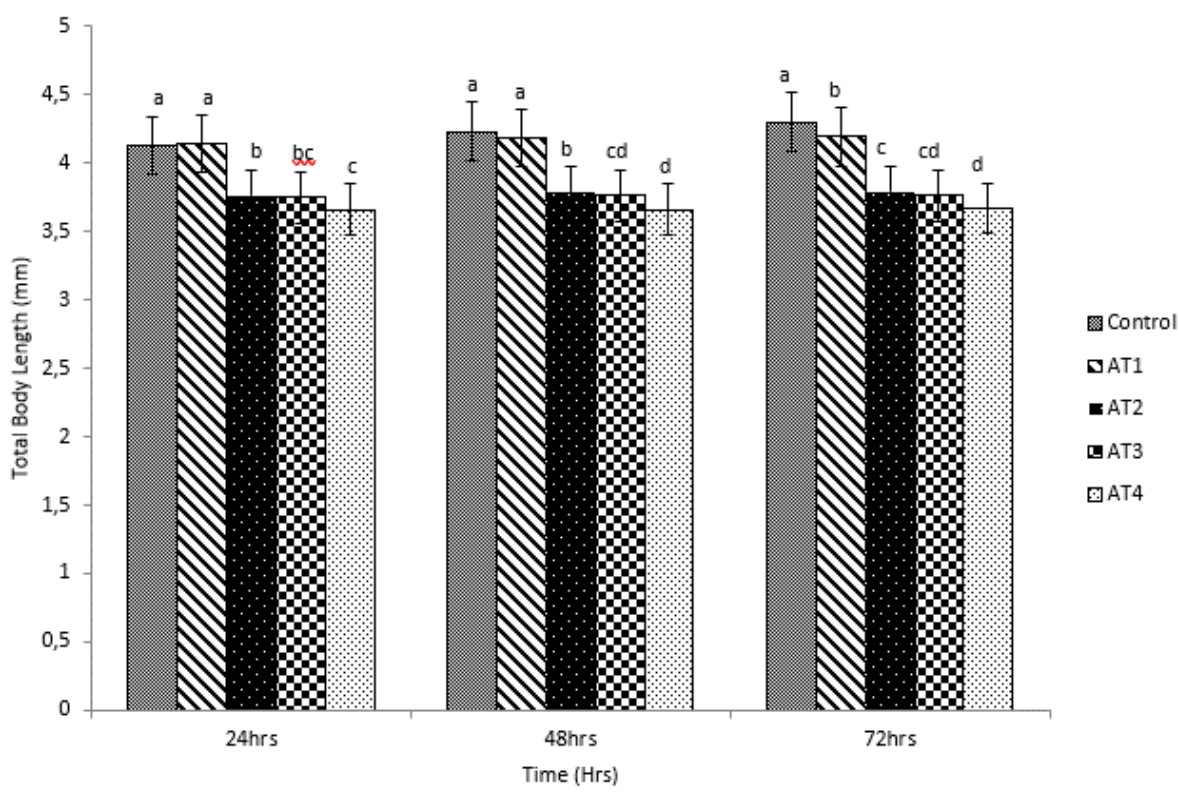

Figure 5. Total body length of Clarias gariepinus larvae exposed to atrazine immediately after fertilization at 24-72 hours posthatching stage $(n=12)$.

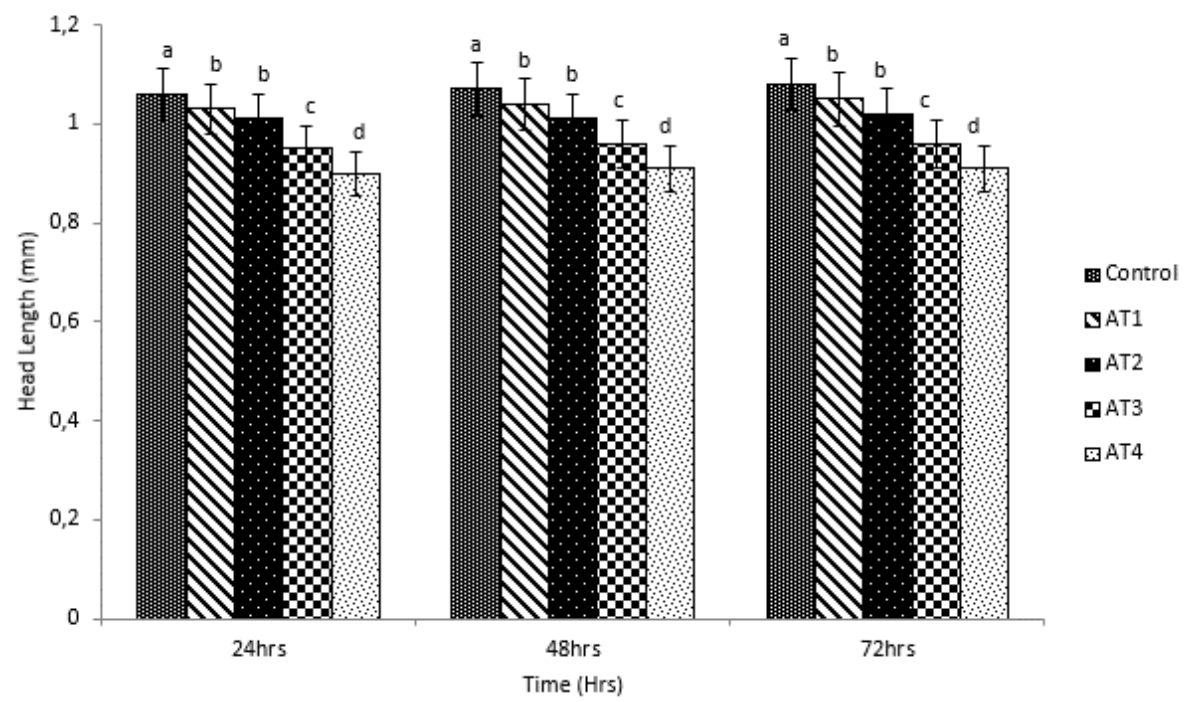

Figure 6. Head length of Clarias gariepinus larvae exposed to atrazine immediately after fertilization at 24-72 hours post-hatching stage $(n=12)$. 


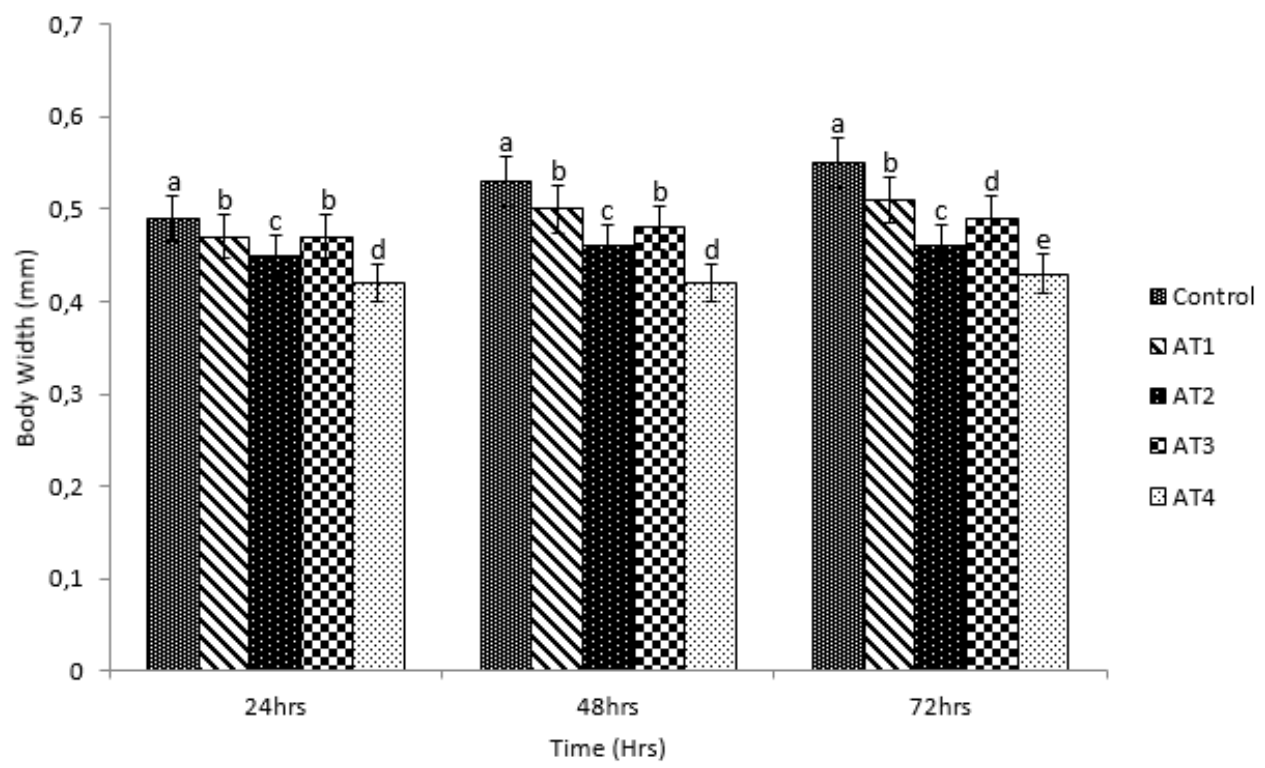

Figure 7. Body width of Clarias gariepinus larvae exposed to atrazine immediately after fertilization at 24-72 hours post-hatching stage $(n=12)$.

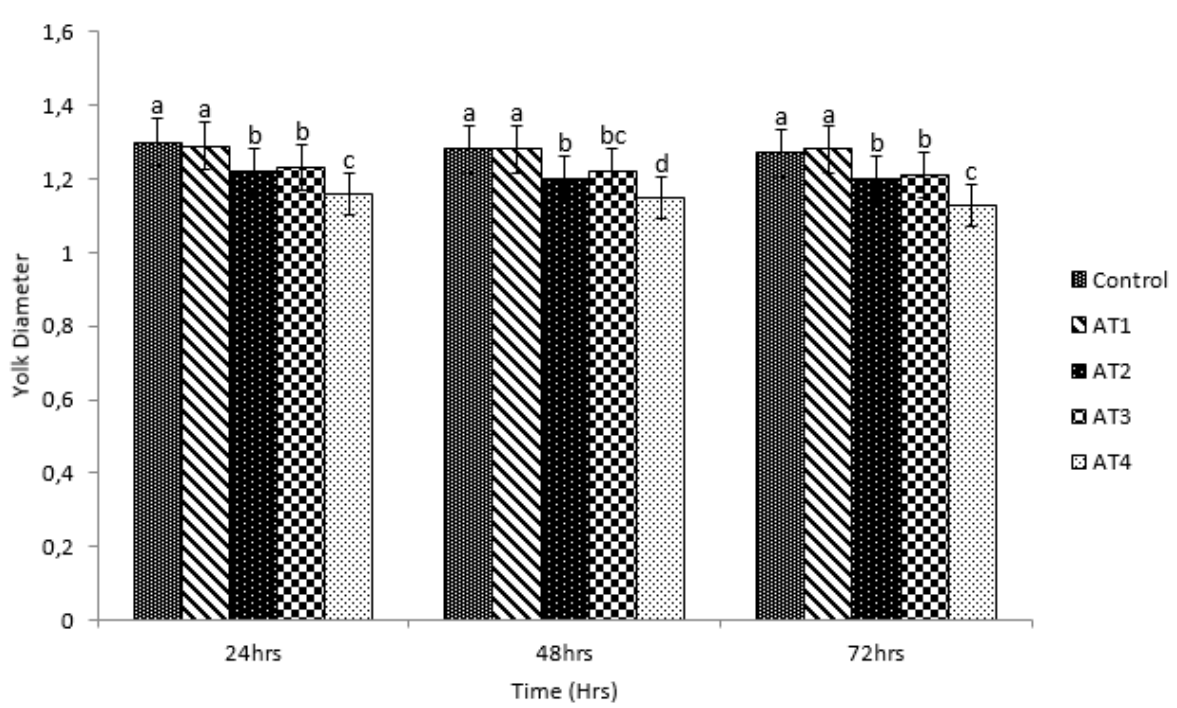

Figure 8. Yolk diameter of Clarias gariepinus larvae exposed to atrazine immediately after fertilization at 24-72 hours post-hatching stage $(n=12)$.

to oxidative stress during certain stages of development, and teratogens that can alter redox statuses, such as thalidomide, phenytoin and ethanol, and disrupt fetal development. Lugowska (2005) stated that normal common carp larvae were 5.5-5.9 mm long under optimal conditions, while those exposed to heavy metals during embryonic development were smaller, some of them less than $5 \mathrm{~mm}$ long. Similar reports have shown in other studies that larvae hatched from metalexposed eggs are smaller than those from an uncontaminated environment (Somasundaram et al. (1984), Kazlauskiene and Stasiunaite (1999).

\section{Conclusions}

This study demonstrates that organisms especially fish are typically very sensitive to toxicological effects at the early stages of their embryonic development.
Therefore, examining organisms at these stages can thus help to evaluate the sub-lethal effect of pesticides and determine the degree of the toxicological effect. Exposure of $C$. gariepinus eggs to atrazine at very low concentrations interfered with successful embryonic development leading to delayed and aborted hatching, growth retardation, as well as severe developmental defects and post-hatching mortalities.

\section{Acknowledgments}

This research has been made possible by the collaboration between Witwatersrand University School of Anatomical Sciences, South Africa and Department of Animal and Environmental Biology, University of Benin, Nigeria. The authors recognize the funding for the Mobility Grant given by the African-German Network of Excellence in Science (AGNES) that enabled Dr Opute to 
spend time in South Africa. The Grant has been generously funded and supported by the Alexander von Humboldt Foundation and the German Federal Ministry of Education and Research. The writers recognize the invaluable contributions of Prof. F.E. Mbajiorgu, Osaro Peter, Iziegbe Iboaya, Agnes Udoko, Faith Uwaifo and Victor Enoma.

\section{References}

Anguiano, O.L, Caballero, A., and Pechen de D'Angelo, A.M. (2001). The role of glutathion conjugation in the regulation of early toad embryo's tolerance to pesticides. Comparative Biochemistry and Physiology, 128:35-43.

Cavas, T., Garanko, N.N., and Arkhipchuk, V.V. (2005). Induction of micronuclei and binuclei in blood, gill and liver cells of fishes subchronically exposed to cadmium chloride and copper sulphate. Food and Chemical Toxicology, 43:569-574

Dennery, P. A. (2007). Effects of oxidative stress on embryonic development. Birth Defects Research Part C, Embryo Today, 81, 155-62.

Gavriloaie, C., and Chişamera, C.h. (2005). Note on the presence of the blunt toothed African catfish Clarias ngamensis Castelnau 1861 (Pisces, Clariidae) in Romania. Travaux du Museum Natinal d'Histoire Naturelle "Grigore Antipa", 48: 309-315.

Gomaah, S.A.A., and El Naggar, G.O. (2004) Proceedings of the first International Conference for Veterinary Research Division, National Research Center

Green, J.D., Mwatibo, J.M., Swartz, W.J. (1997). The effects of methoxychlor on early sea urchin development. Environmental Research, 72(1):56-64

Jezierska, B., Ługowska, K., and Witeska, M., (2009). The effects of heavy metals on embryonic development of fish (a review). Fish Physiology and Biochemistry, 35:625640.

Jezierska, B., Lugowska, K., Witeska, M., and Sarnowski, P. (2000) Malformations of newly hatched common carp larvae. Electronic Journal of Polish Agricultural Universities, 3(2): \#1

Kazlauskiene, N., and Stasiunaite, P. (1999). The lethal and sublethal effect of heavy metal mixture on rainbow trout (Oncorhynchus mykiss) in its early stages of development. Acta Zoological Lituanica Hydrobiology, 1:47-54

Kucharczyk, D., Kucharczyk, D.J., Nowosad, J. and Omirzhanova, N. (2019) Optimization of artificial insemination outcomes of African catfish (Clarias gariepinus) with differing hatchery conditions. Animal Production Science, 211:106222

Leung, C., Webb, S.E., and Miller A. (1998) Calcium transients accompany ooplasmic segregation in zebrafish embryos. Development Growth and Differentiation, 40:313-326

Linda, A., Harrison, M.D., Dolores, H., Pretorius., M.D., Nancy, E., and Budorick, M.D. (1992). Abnormal Spinal Curvature in the Fetus. Journal of Ultrasound Medicine, 11:473-479

Ługowska, K. (2005). The effects of copper and cadmium on embryonic development, and quality of newly hatched common carp (Cyprinus carpio L.) larvae. Ph. D Thesis, University of Podlasie (In Polish) pp 127
Ługowska, K., and Witeska, M., (2008). The effect of copper exposure during embryonic development on deformations of newly hatched common carp larvae, and further consequences. Fisheries, 7: 1-5.

Mochida, K., Ito, K., Harino, H., Tanaka, H., Onduka, T., Kakuno, A., and Fujii, K. (2009) Inhibition of acetylcholinesterase by metabolites of copper pyrithione (CUPT) and its possible involvement in vertebral deformity of a CuPTexposed marine teleostean fish. Comparative Biochemistry and Physiology Part C Toxicology \& Pharmacology, 149(4):624-30

Müller, T., Ácsb, E., Beliczkyd, G., Makke, J., Földib, A., Kucskaf, B., Horvátha, L., Ittzésa, A., Hegyia, A., Szabóa, T., Urbányia, B., Quyena, N.N., Orbáng, L. and Havasid, M. (2020) New observations about the fertilisation capacity and latency time of sperm inseminated into the ovary of African catfish (Clarias gariepinus), an oviparous modelfish, Aquaculture, 555:735109

Nowosad, J., Sikora, M., and Kucharczyk, D. (2018) Survival rates and the occurrence of larval malformations, including Siamese twins, following fertilization of postovulatory aged oocytes in ide (Leuciscus idus), Diseases of Aquatic Organisms, 127: 237-242

Ozkan, F., Gunduz, S.G., Berkoz, M., Ozluer, H.A. (2011). Induction of micronuclei and other nuclear abnormalities in peripheral erythrocytes of Nile tilapia, Oreochromis niloticus, following exposure to sublethal cadmium doses. Turkish Journal of Zoology, 35:585-592

Ponzoni, R.W. and N.H. Nguyen (eds). (2008) Proceedings of a Workshop on the Development of a Genetic Improvement Program for African catfish Clarias gariepinus. World Fish Center Conference Proceedings Number 1889. The World Fish Center, Penang, Malaysia. $130 \mathrm{pp}$

Rocha, C.A.M, Almeida, V.H.C., Silva Pinheiro, R.H.S., and Cunha, L.A. (2010). Micronuclei and other nuclear abnormalities in acara Aequidens tetramerus (Perciforms: Cichlidae) exposed to copper sulfate. UAKARI, 6:57-66

Samarin, A.M., Blecha, M., Bytyutskyy, D., and Policar, T. (2015) Postovulatory oocyte ageing in pikeperch (Sander lucioperca L.) and its effect on egg viability rates and the occurrence of larval malformations and ploidy anomalies. Turkish Journal of Fisheries and Aquatic Sciences, 15: 429-435

Samarin, A.M., Zarski, D., Palin' ska-Zarska, K., Krejszeff, S., Blecha, M., Kucharczyk, D., and Policar, T. (2017) In vitro storage of unfertilized eggs of the Eurasian perch and its effect on egg viability rates and the occurrence of larval malformations. Animal 11: 78-83

Scahill, J.L. (2008) Effects of atrazine on embryonic development of fathead minnows (Pimephales promelas) and Xenopus laevis, BIOS 79(4): 139-149

Sisman, T., Atamanalp, M., Dane, H., and Adil, S. (2016) The toxicity of $10 \mathrm{~W}-40$ motor oil on zebrafish early life stages. Turkish Journal of Fisheries and Aquatic Sciences, 16: 597-604

Słomin'ska, I. (1998). Sensitivity of early developmental stages of common carp (Cyprinus carpio L.) to lead and copper toxicity. Ph. D Thesis, Inland fisheries Institute, Olsztyn, pp 104 (In Polish)

Somasundaram, B, King, PE, and Shackley, S. (1984) The effects of zinc on postfertilization development in eggs of Clupea harengus L. Aquatic Toxicology, 5:167-178 